\title{
Processing Of The Danish C-band SAR Data
}

\section{Madsen, Søren Nørvang; Dall, Jørgen}

Published in:

10th International Geoscience and Remote Sensing Symposium

Publication date:

1990

Document Version

Publisher's PDF, also known as Version of record

Link back to DTU Orbit

Citation (APA):

Madsen, S. N., \& Dall, J. (1990). Processing Of The Danish C-band SAR Data. In 10th International Geoscience and Remote Sensing Symposium: Remote Sensing Science for the Nineties (pp. 2029-2032). IEEE.

\section{General rights}

Copyright and moral rights for the publications made accessible in the public portal are retained by the authors and/or other copyright owners and it is a condition of accessing publications that users recognise and abide by the legal requirements associated with these rights.

- Users may download and print one copy of any publication from the public portal for the purpose of private study or research.

- You may not further distribute the material or use it for any profit-making activity or commercial gain

- You may freely distribute the URL identifying the publication in the public portal

If you believe that this document breaches copyright please contact us providing details, and we will remove access to the work immediately and investigate your claim. 


\section{PROCESSING OF THE DANISH C-BAND SAR DATA}

Søren Nørvang Madsen and Jørgen Dall

Technical University of Denmark

Electromagnetics Institute, Build. 348

DK-2800 Lyngby, Denmark

\section{ABSTRACT}

A new Danish C-band SAR was tested in the fall of 1989. As part of the system a very flexible software processor has been developed. The processor is designed to serve several purposes such as experimental test and analysis processor, real-time processor development tool, and operational off-line processor. The processor also holds substantial motion compensation features, and they are described too. In the initial test a 2 by $2 \mathrm{~m}$ resolution was verified by analysis of echoes from corner reflectors.

Keywords: C-band SAR, software processor, motion compensation.

\section{INTRODUCTION}

In January 1986 a new remote sensing activity was initiated at the Electromagnetics Institute of the Technical University of Denmark (TUD). The Institute started the construction of an airborne Synthetic Aperture Radar, SAR, operating at C-band. The project is denoted Coherent Radar and Advanced Signal processing (KRAS) and it is primarily sponsored by the Thomas B. Thriges Foundation. The main objective is to design a very flexible radar that can be set up for many different applications including ERS-1 underflights.

Late 1989 the first flight tests were conducted, and the design and construction of an airborne real-time processor was initiated. Also the activities were extended to include development of a prototype dual polarized antenna. This is a first step towards a later upgrade to full polarimetric capability.

The requirements to the software SAR processor are that it must have the capabilities to support the flexibility of the radar, it must serve as a development tool in the test and integration phase, it must be able to simulate the algorithms being considered for the real-time processor, and it should form the basis of an operational processor where throughput and calibration are important considerations.

\section{THE TUD SAR SYSTEM}

This section gives an introduction to the KRAS SAR. A detailed description is found in [1] and [2]. The radar operates at $5.3 \mathrm{GHz}$, and has a bandwidth of $100 \mathrm{MHz}$. It uses digital techniques to generate the transmitted waveform, and system timing (such as pulse repetition frequency and sampling frequency) is set on-line by the control computer. The code transmitted (e.g. linear or nonlinear FM), the length of the transmitted pulse, and the bandwidth can be controlled in-flight. Accordingly, it is also possible to trade-off the use of the $\mathbf{8 1 9 2}$ complex range-cells. If $1.5 \mathrm{~m}$ range pixel spacing is selected, it gives a "raw" slant range swath of $12 \mathrm{~km}$ and $6 \mathrm{~m}$ spacing gives $48 \mathrm{~km}$ swath etc. Similarly the along track sampling can be chosen in-flight. The nominal along track sampling mode applies a PRF, which is locked to the aircraft ground speed (from an INU, Inertial Navigation Unit, mounted close to the antenna), so that the spacing in meters is maintained constant, but a constant PRF can alternatively be selected. The INU is also used to acquire other motion parameters needed for motion compensation.

The antenna is a $1.2 \mathrm{~m}$ long vertically polarized slotted waveguide array with a $30^{\circ}$ elevation beamwidth, which resembles a cosec-square pattern. It is installed in a modified external fuel tank on a Gulfstream G-3 jet aircraft of the Royal Danish Air Force. The antenna is three-axis stabilised and the antenna look-angle can be controlled, to enable the imaging of all incidence angles from $20^{\circ}$ to $90^{\circ}$. The $2 \mathrm{~kW}$ transmitter peak power gives a system range of $80 \mathrm{~km}$. The aircraft operates nominally at an airspeed of $465 \mathrm{knt}$, at altitudes up to $45.000 \mathrm{ft}$, and it has a range of more than $7000 \mathrm{~km}$.

\section{THE TUD SOFTWARE PROCESSOR}

The SAR processing software is based on the rangeDoppler algorithm [3], which corrects for the range curvature by means of interpolated range shifts in the rangeDoppler domain. Other algorithms including the nonseparable algorithm [4] and the step transform [5] have also been considered. However, the nonseparable algorithm is very inefficient in the KRAS case where the depth of focus is much smaller than the pulse length, and 
the step transform does not meet the requirements set up for the integrated side lobe ratio and the geometric distortion. Therefore the range-Doppler algorithm was adopted. As illustrated in Fig. 1a, fast convolution with the FFT plays an important role in this algorithm. Potential advantages of using an alternative fast transform or convolution algorithm have been studied, [6], but the FFT proved the most suitable, one reason being that some of its alternatives call for special-purpose hardware.

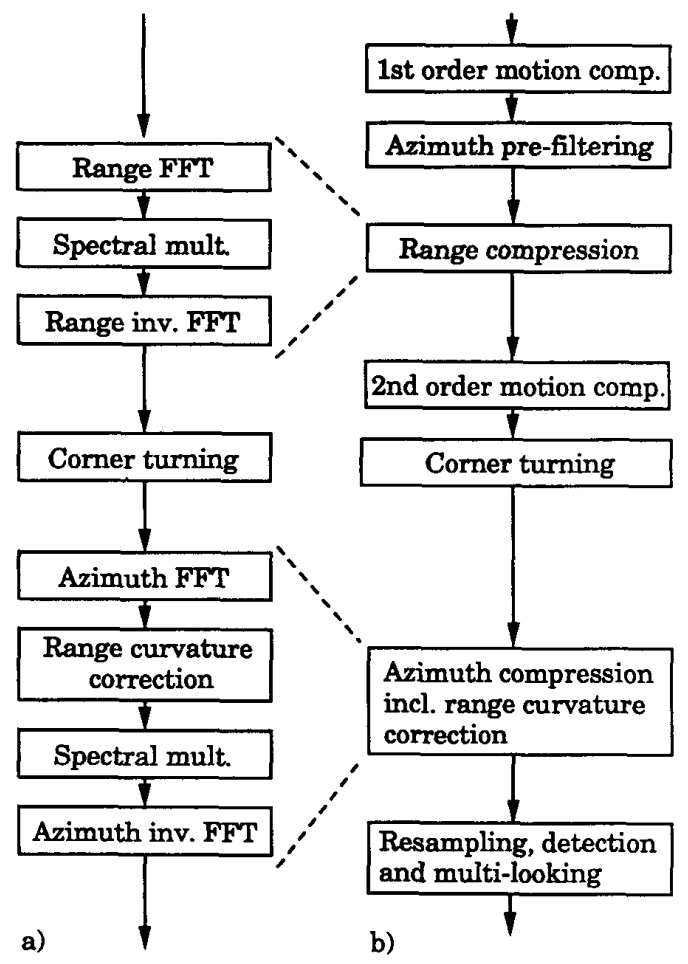

Fig. 1. The range-Doppler algorithm a) and a typical configuration of the KRAS software processor $b$ ).

The current off-line processor is an experimental processor primarily designed to support the development of the radar system and the real-time processor. This means that flexibility has a high priority compared to processing speed and user interface.

The processor is divided into a number of separate modules which communicate with one another via disk files of a standardized format. In addition to the modules shown in Fig. Ib the processor includes analyzing modules such as histogram monitor, Doppler centroid estimator, Doppler rate estimator (basis of a future autofocus module), plot interpolator and display controller. The pre-filtering and motion compensation modules shown in Fig. $1 \mathrm{~b}$ are described in the next section. The modular approach allows raw SAR data to be processed by only a subset of the modules, i.e. the processing can be stopped or paused at any stage. Furthermore, it enables the sequence of the processing to be changed. The modules listed in Fig. $1 \mathrm{~b}$ can be seen as building blocks which can, in principle, be combined at will. However, it is important to note that only successive linear processes can be interchanged. As an example, even if it would reduce the processing time the azimuth pre-filtering and the first order motion compensation cannot be interchanged because the latter is nonlinear. (In practice they can if the motions to be compensated for are slow compared with the bandwidth of the prefilter).

The experimental processor takes about 4 hours to process a 9 by $6 \mathrm{~km}$ image into $2 \mathrm{~m}$ resolution. At the moment images larger than 9 by $6 \mathrm{~km}$ cannot be processed due to disk constraints. Airborne hardware implementations of the first order motion compensation and the azimuth pre-filter have been developed, and they are expected to be operational in the spring 1990 . At this point 9 by $24 \mathrm{~km}$ images can be processed. The expected processing time is 12 hours. A future operational software processor will be optimized with respect to the throughput by eliminating disk accesses between some of the modules shown in Fig. 1b.

\section{MOTION COMPENSATION}

The SAR principle relies on the assumption that the radar moves along a smooth known trajectory, in the aircraft case a straight line. When this is not actually the case, motion compensation must be applied. Motion compensation will nearly always be required when high resolution is desired. However, motion compensation is a very delicate affair. The principle and some fundamental problems will be outlined in the following.

The first problem is to measure where the radar is relative to where it should be. This is usually done by an INU, which relies on gyros for measuring angles, and accelerometers for measuring displacements. The practical problems, however, are significant. They include quantization errors, insufficient sampling frequency, time delay of the output, sensor drift etc. These problems have been described in [7].

The second problem is then to find the line of sight vector from radar to target. According to Fig. 2 the slant range displacement that needs to be corrected is given by:

$$
\Delta R=\vec{n}_{L O S} \cdot \Delta \vec{r}_{\text {ant }}=\left|\Delta \vec{r}_{\text {ant }}\right| \cdot \cos \left(\theta_{\text {ant }}-\theta_{L O S}\right)
$$

where $\vec{n}_{L O S}$ is a unit vector in the line of sight (LOS) direction, $\Delta \vec{r}_{\text {ant }}$ is the antenna displacement vector, and $\theta_{\text {ant }}-\theta_{L O S}$ is the angle between $\vec{n}_{L O S}$ and $\Delta \vec{r}_{\text {ant }}$ (angles are measured relative to vertical). However the LOS angle is not known. Only the slant range, and a platform altitude relative to average terrain is available. It is easily shown that an altitude error of $\Delta h$ will give rise to an angle error 


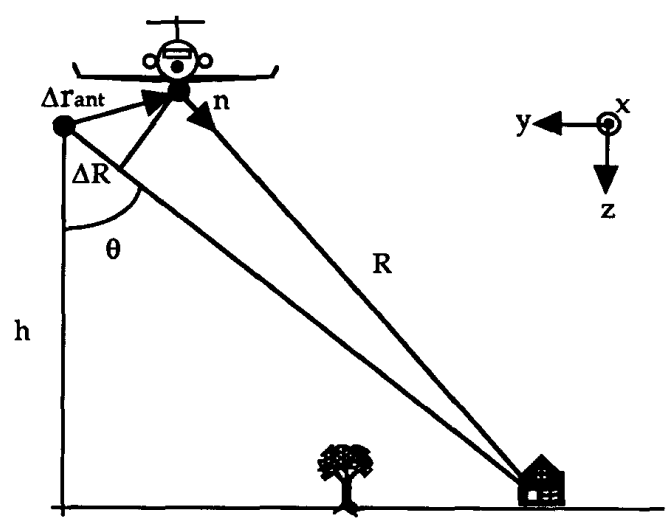

Fig. 2. The geometry involved in performing motion compensation.

$\Delta \theta$ given by:

$$
\Delta \theta=\frac{\Delta h}{R \cdot \sin \theta_{L O S}}
$$

where $\theta_{L O S}$ is equal to the expected angle $=\operatorname{arcos}(h / R)$. It is seen that for satellite simulation under-flights, where the angle of incidence is small $\left(20^{\circ}-30^{\circ}\right)$ it is extremely difficult to determine the LOS angle accurately. At $20^{\circ}$ incidence angle and $10 \mathrm{~km}$ altitude even $50 \mathrm{~m}$ height uncertainty will give $1^{\circ}$ uncertainty on the LOS angle. This corresponds to a residual error of $1.5 \%$ on the motion to be compensated. The philosophy is obviously: "Use a stable platform".

The implementation of a computationally efficient system is also difficult. In principle all received echoes should be range compressed to obtain an accurate slant range measurement before motion compensation. However, the KRAS radar operates at higher PRFs than needed to achieve the desired azimuth resolution, as this improves the signal-to-noise ratio. The data rate is reduced (usually by a factor of 4 or 8 ) with an azimuth prefilter which filters and subsamples the data in the along track dimension. By performing the range compression after the azimuth pre-filtering the computational load, which is particularly important in a real-time implementation, can be significantly reduced.

Since the azimuth pre-filter is a Doppler lowpass filter, or one could say a short first order beam-forming filter, data should be motion compensated before the pre-filter. However, it has been found, [8], that the apertures formed by the pre-filter are so short, that it is sufficient to phase compensate the data before the pre-filter; range migration correction can be performed afterwards. Furthermore, it has been found that the signal will not be significantly attenuated $(<0.3 \mathrm{~dB})$ in the pre-filter even if the same phase correction is used for all ranges. The pro- cessing sequence is therefore as shown in Fig. 1b where "1st order mocomp." is a common phase shift of an entire range line and "2nd order mocomp." performs a phase correction and a range migration correction as a function of range (the range shift already performed must be subtracted).

A major problem in the present system is that the INU velocities drift with time. Since the antenna pointing is controlled by the INU this results in a mispointing of the antenna relative to true cross track. Also it gives rise to errors in the along track velocity estimate, which in turn causes focusing problems, especially at long range. To enable updates to the INU velocities a Doppler tracker has been included in the KRAS radar. The Doppler tracker is implemented using the "sign-Doppler" algorithm, [9], and it estimates the Doppler centroid as a function of slant range (or the corresponding incidence angle, $\left.\theta_{L O S}\right)$. According to the geometry in Fig. 2 the Doppler shift is given by:

$$
f_{D}=\frac{2}{\lambda}\left(v_{y} \sin \theta_{L O S}-v_{z} \cos \theta_{L O S}\right)
$$

From this equation the cross track velocities can be estimated by inserting the Doppler estimates and the corresponding incidence angles.

The $v_{x}$ velocity is actually the most critical parameter for long range high resolution mapping. The tolerance on $v_{x}$ corresponding to $45^{\circ}$ quadratic phase error is:

$$
\Delta v_{x}=\frac{v_{x}\left(\rho_{\mathrm{a}}\right)^{2}}{\lambda R}
$$

where $\rho_{\mathrm{a}}$ is the azimuth resolution. To achieve a $1 \mathrm{~m}$ resolution at $80 \mathrm{~km}$ range requires an accuracy of $0.06 \mathrm{~m} / \mathrm{s}$ on the along track velocity! One-way to update $v_{x}$ is from autofocus estimates.

\section{PRELIMINARY RESULTS}

The first tests of the system where conducted in the fall 1989. Motion compensation was not applied during the first mission, and an $8 \mathrm{~m}$ resolution was obtained. Copenhagen and the TUD were mapped in the second mission. Data were recorded from an altitude of $41.000 \mathrm{ft}$ $(\approx 12.500 \mathrm{~m})$ at slant ranges from $22,000 \mathrm{~m}$ to $34,000 \mathrm{~m}$. Motion compensation was applied, and three corner reflector were deployed on a low backscatter background (a soccer field) at the TUD. Fig. 3 shows the test site. STC (sensitivity time control) was not used during recording. The equalization of the radiometric response across the swath is entirely due to the antenna shaping. It is noted that there are no interference fringes indicating reflections from the wing, and there is no "banding" effect in the along track direction indicating motion compensation problems. 


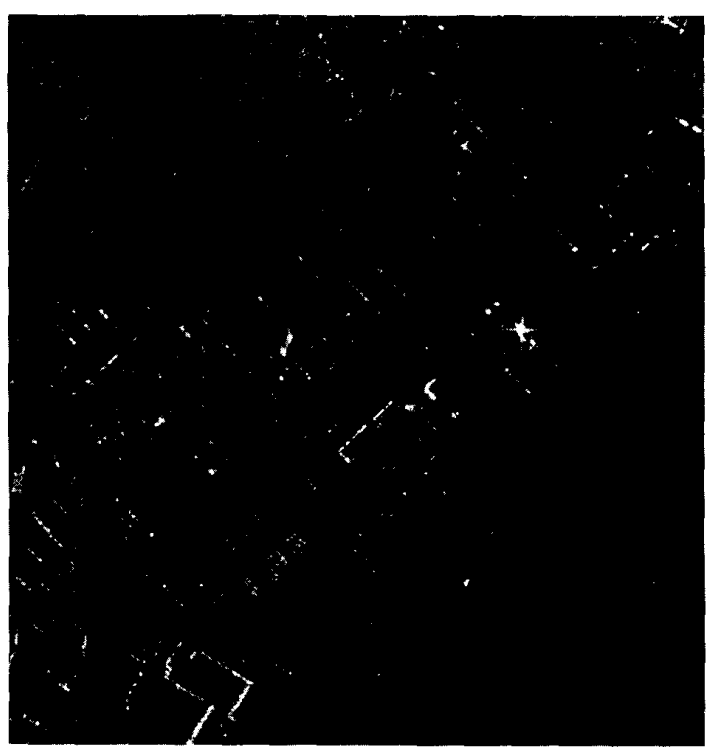

Fig. 3. A small image subsection of 1.5 by $1.5 \mathrm{~km}$ showing the Technical University of Denmark. In the upper right corner is a "dark" soccer field ( 200 by $200 \mathrm{~m}$ ) where three corner reflectors were located. The bright star below the corner reflectors is due to a pool with a metal-profile wall just next to it.

Fig. 4 shows an 3-D plot of the area with the three corner reflectors. Interpolated plots of the corner reflectors indicate a $3 \mathrm{~dB}$ resolution of $2.0 \mathrm{~m}$ in range and $2.1-2.2 \mathrm{~m}$ in azimuth (weighting was applied in both range and azimuth).

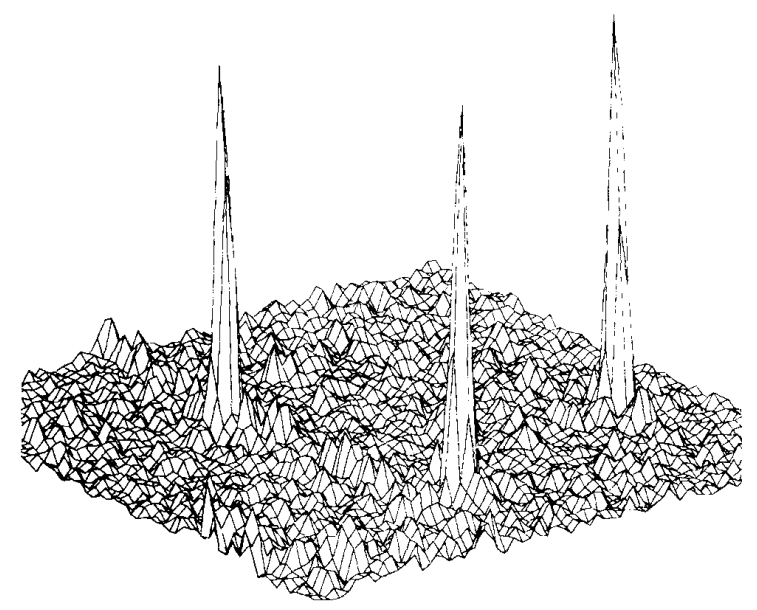

Fig. 4. 3D-plot of the corner reflectors (linear amplitude scale).

\section{SUMMARY}

The Danish SAR has now successfully completed the initial tests. A serie of test flights and updates will take place in the spring and summer of 1990. During this period the performance of the motion compensation facilities, and the built-in calibration facilities [10] will be analyzed. A number of operational features such as the inflight velocity update and the real-time pre-filters for both range and azimuth will be tested. The design of the real-time processor will be accelerated, and the resently funded development of a prototype dual-polarized microstrip antenna will commence. This work is aiming at a later update of the system to full polarimetric capability

\section{REFERENCES}

[1] N. Skou, S. N. Madsen, and E. Lintz, Christensen, "The TUD C-band SAR", IGARSS'88, pp. 1039-1040, 1988.

[2] S. Nørvang Madsen, N. Skou and E. Lintz Christensen, "A New C-band SAR for ERS-1 Underflights", RADAR 90 conf. proc.

[3] C. Wu, K.Y. Liu and M. Jin, "Modeling and a correlation algorithm for spaceborne SAR signals", IEEE Trans. Vol. AES-18, No. 5, pp. 563-574, Sep. 1982.

[4] A. Di Cento, "A New Look at Norseparable Synthetic Aperture Radar Processing", IEEE Trans., Vol. AES-24, No.3, pp. 218-224, May 1988.

[5] M. Sack, M. R. Ito and I. G. Cumming, "Application of efficient linear FM matched processing", IEE Proceedings, Vol. 132 Pt. F, No. 1, pp. 45-57, Feb. 1985.

[6] J. Dall, "Fast convolution algorithms for SAR processing", Proc. of the Int. Conf. on Radar, Paris, 1989, pp. 226-231.

[7] J. L. Farrell, J. H. Mims, and A. Sorrell, "Effects of Navigation Errors In Maneuvering SAR", IEEE Trans., Vol. AES-9, No. 5, pp. 758-776, Sep. 1973.

[8] P. Wieslander Madsen, "Estimation of aircraft motions from coherent radar data" (in Danish), M.Sc Thesis, Electromagnetics Institute, Tech. Univ. of Denmark, Aug. 1988.

[9] S. Nørvang Madsen, "Estimating The Doppler Centroid of SAR data", IEEE Trans., Vol. AES-25, No. 2, pp. 134-140, March 1989.

[10] N. Skou, S. N. Madsen, E. Lintz Christensen, A. Netterstrøm, and K. Woelders, "The Danish C-band SAR - Calibration Accuracy and Stability", IGARSS 90. 